\title{
The Stz'uminus Storied Places Project: A Community-Based Digital Mapping Project to Mobilize Indigenous Place Names and Place-based Stories
}

\author{
AMY BECKER* \\ University of Victoria \\ beckera@uvic.ca
}

\begin{abstract}
Many layers of knowledge are embedded within Indigenous-language place names, including, but not limited to, the physical appearance of the environment, resource procurement, cultural identity, history and place-based stories. In the face of the increasingly prevalent reality that Elders are passing away and taking with them a wealth of knowledge, it is crucial that Indigenous place names and the stories associated with them are documented and passed to younger generations. The Stz'uminus Storied Places Project aims to mobilize place-based knowledge about Stz'uminus traditional territory through a community-based research process, where youth meet with Elders and film their place-based stories, as well as a video-embedded digital map. The interactive digital map, with its ability to embed layers of multi-media,
\end{abstract}

\footnotetext{
"This research is underway under the direct supervision of Dr. Brian Thom and was supported by the Jamie Cassels Undergraduate Research Award (JCURA) through the Vice President Academic and the Learning and Teaching Centre at the University of Victoria. I express my special appreciation and gratitude to my JCURA supervisor Dr. Brian Thom for his guidance, mentoring, and constant encouragement of my contribution to this project. Thank you to Shirley Louie for her enthusiasm for the creation of the map, her dedication to organizing youth-Elder meetings, and for garnering the community's support. A special thank you to Stz'uminus Elders who have shared their stories and knowledge so far and to the youth who have listened to and digitally recorded those stories. Thank you to Project REEL Life and Joshua Raven for their continual support with gear and technical guidance.
} 
attempts to document and communicate an integrated representation Indigenous perspectives of named places.

Keywords: Indigenous place names; digital mapping; Hul'qumi'num; Stz'uminus First Nation; Google mapping; place-based stories

\section{INTRODUCTION}

$\mathrm{M}$ APS ARE POWERFUL DOCUMENTS. They have been used as instruments of colonial power and tools for formalizing borders and economic power relations (Harley, 1991). In recent years, Indigenous place names maps became a form of "countermapping” (Peluso, 1995). First Nations used these maps to document their people's names for the land in their local languages - a way of re-claiming and re-naming the landscapes their ancestors inhabited for thousands of years (Usher, 2003; Wonders, 1987). However, Indigenous place names are not simply geographic identifiers; they are houses for layers of information, including cultural and historical knowledge, environmental conditions, availability of resources, and Aboriginal identity (Müller-Wille, 1989; Thorton, 1997; Cruikshank, 1990). In the face of the increasingly prevalent reality that Elders are passing away and taking with them a wealth of knowledge, it is crucial that these names and the stories associated with them are documented and passed on to younger generations before the knowledge is lost. Before the advent of easily accessible mapping technologies, Indigenous place names were documented on paper maps, such as the one the Stz'uminus Storied Places Project is based on (Figure 1).

However, static two-dimensional paper maps do little to convey the rich layers of information associated with Indigenous place names and their stories. By comparison, a digital map of place names can display many layers of information. For example, when a user clicks on a place name on a digital map, a pop-up box appears displaying various multi-media, such as video, audio, images and text (Figure 2). In this paper, I argue that a digital, interactive place names map, embedded with information collected by Stz'uminus First Nation youth for the Stz'uminus Storied Places Project, has the potential to doc- 
Figure 1: Ladysmith Area Hul'qumi'num Place Names, Hul'qumi'num Treaty Group, 2005.

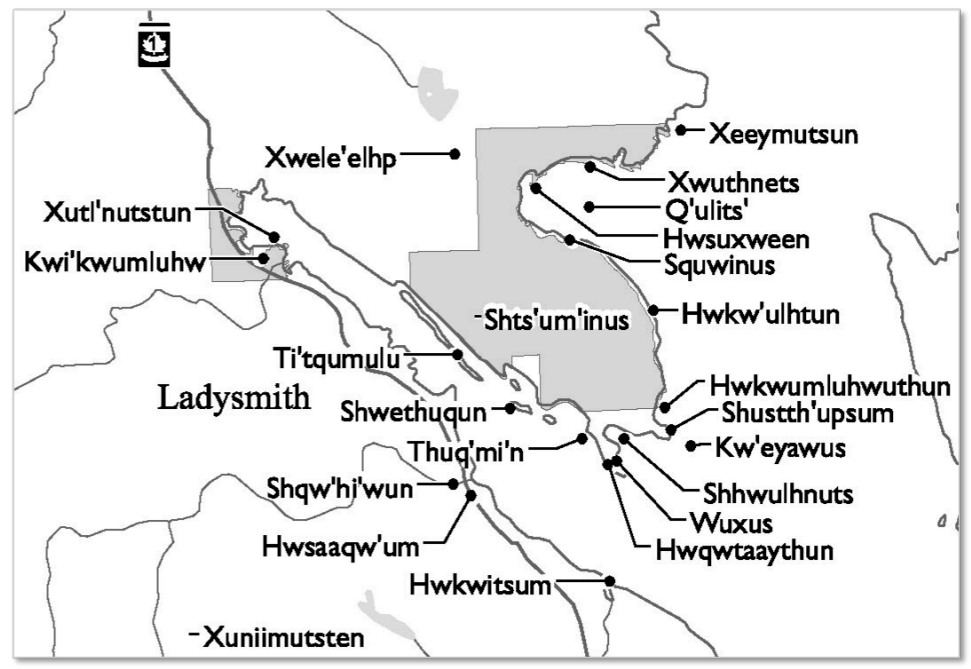

ument, mobilize, and preserve the many layers of knowledge contained within Hul'qumi'num-language place names, both through the project's research process and the research product. By drawing on the academic place-names literature, I argue that the digital map presents a more integrated view of Indigenous perspectives of the environment, unifying the many layers of knowledge associated with place names in an easy-to-use interactive mapping platform, and the community-based research process has the potential to propel place name knowledge into active use by the community. Finally, I provide a brief overview of the strengths and weaknesses of the digital mapping tools used during this project.

\section{PROJECT BACKGROUND}

The Stz'uminus Storied Places Project emerged by building off of the momentum and strength of a grass-roots digital story-telling initia- 
Figure 2: Pop-up box for place name "Xeeymutsun" on the Stz'uminus Storied Places Atlas, Map data: Google

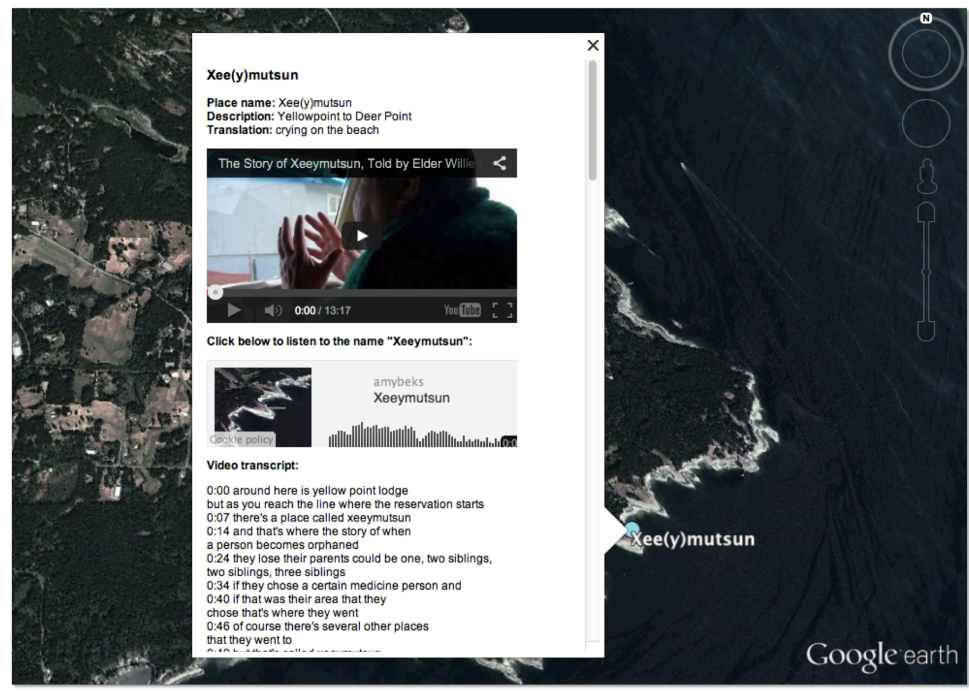

tive called Project Reel Life during its final months of activities. During this initiative, youth from Stz'uminus were meeting with their Elders and recording stories. At an Elders dinner on October 2013, Dr. Brian Thom, UVic Associate Professor of Anthropology, and I, a UVic Anthropology undergraduate student, proposed the idea of a digital place names map embedded with place-based stories as an additional outcome of the Project Reel Life initiative. The Elders welcomed the idea of a digital map that incorporated place-based stories about Stz'uminus traditional territory, and after that, Project Reel Life's focus for meetings between youth and Elders shifted to Hul'qumi'numlanguage place names and the stories attached to those named places. After the Project Reel Life initiative wrapped up, we secured funding for an additional 10 interviews and began planning for the Stz'uminus Storied Places Project. 


\section{ReseArcher ROLE AND PROJECT STATUS}

My main role during the preliminary stages of the Stz'uminus Storied Places Project was to compile a map prototype using Google mapping tools and communicate with the project's community lead and Chief and Council to plan next steps. For the map prototype, I compiled data using two free Google mapping tools, Google Earth and Google Maps Engine, and explored both tools' functionality in the context of the project. The data added to the prototype map included videos from one Elder, Mr. Willie Seymour, recorded during the Project Reel Life initiative, and archival information about Hul'qumi'num place names. The digital map prototype is categorized with Hul'qumi'num place names, with each place name being a point on the map and the information embedded at that point being specific to that place name.

The next steps for the project include organizing ten more meetings with Elders and youth to record place-based stories, editing the footage from those ten interviews and additional relevant footage from the Project Reel life initiative, and presenting the videos to an Elders committee for guidance on what can be posted publically to the digital map and what must remain private and archived. The Project's community lead organizes between three and ten youth, usually between the ages of 12 and 16, to go on outings with Elders and I will attend those meetings to help with filming and interviewing. We also plan to hold one to two mapping workshops with the youth, conduct in-depth training with one or two interested community members, and create manuals for how to continue to add to and change the map as the community sees fit. The community hopes to see the Stz'uminus Storied Places digital map used as a teaching tool in the local school as well as a communication tool to raise awareness of Stz'uminus traditional territory to the general public.

\section{Stz'uminus First NAtion}

Members of the Stz'uminus First Nation are a Coast Salish people located on the east coast of Vancouver Island. The Stz'uminus First 
Figure 3: Chemainus Indian Reserve No. 13 (IR 13), Map data: Google, IMTCAN.

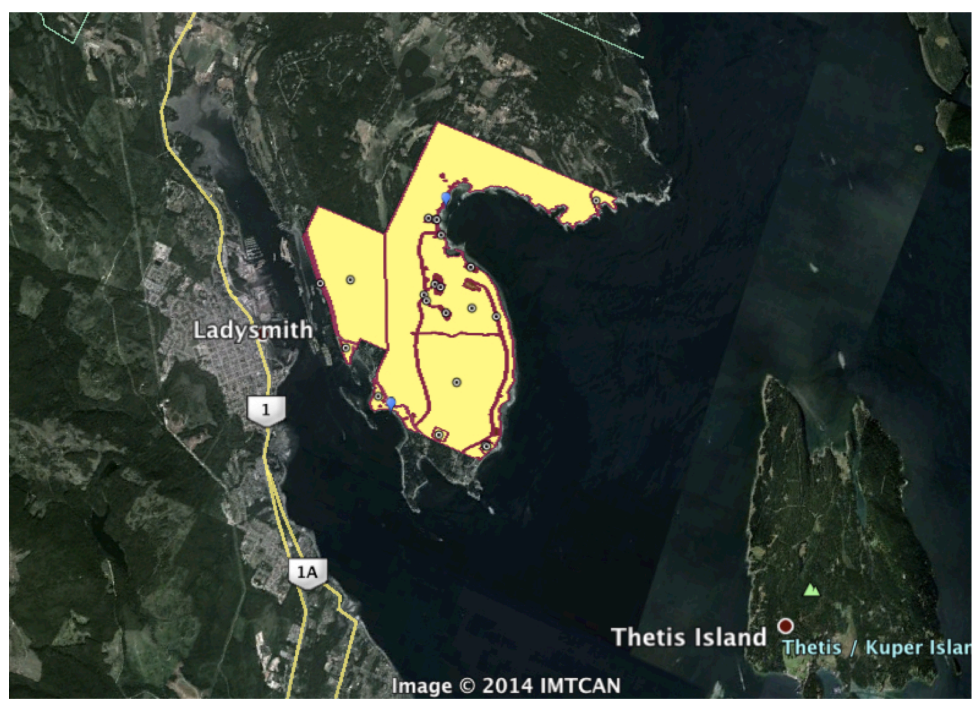

Nation's largest Indian Reserve, Chemainus Indian Reserve No. 13 (IR13), borders the Ladysmith Harbour and the Stuart Channel (Figure 3). As a Coast Salish people, however, the Stz'uminus First Nation's traditional territory extends well beyond the borders of their reserve land, encompassing most of the Southern Gulf Islands as well as areas along the Fraser River on the mainland (Figure 4). The Nation has around 1, 300 members with about half living on reserve (Stz'uminus First Nation, "Our Story," n.d.). The local language is Hul'qumi'num. While many Hul'qumi'num place names have been recorded for the Stz'uminus First Nation's traditional territory (HTG, 2005), for the purpose of this study we focus on gathering stories for 21 place names in and around IR 13 and the Ladysmith Harbour. 
Figure 4: Stz'uminus First Nation Territory, Community map: Stz'uminus First Nation, n.d.

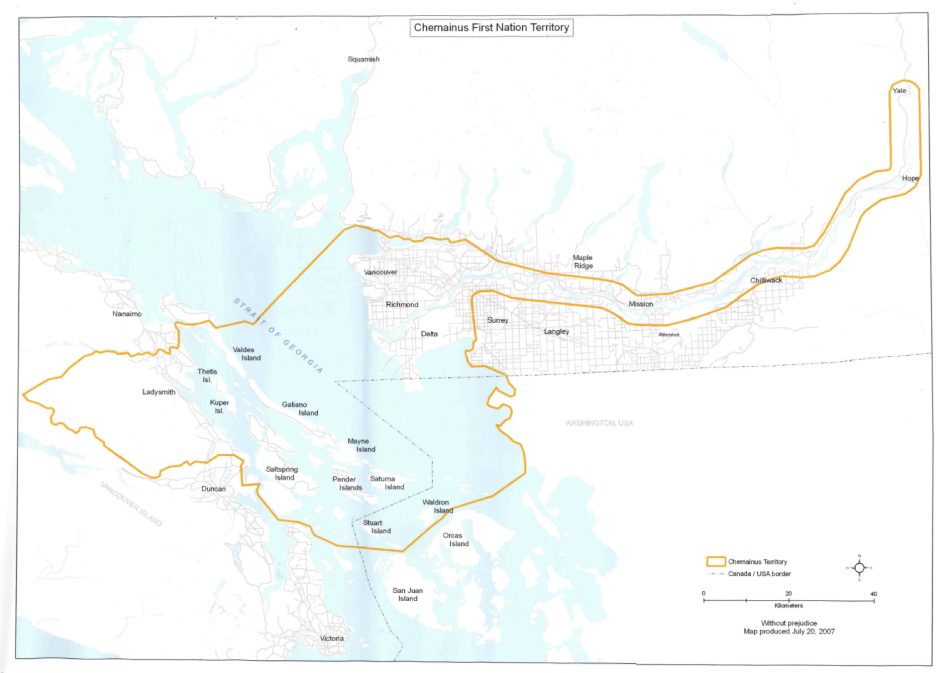




\section{REPRESENTING A PLACE NAME'S MEANING ON A MAP}

Indigenous place names are age-old words packed with meaning that provides a physical and cultural context. They are what Thorton (1997) calls "linguistic artifacts," housing meaning that extends hundreds of years back in time (p. 222). Indeed, the meanings of many place names have long been obscured due to language and culture shifts over extended periods; however, those names are still known and used by Aboriginal peoples today, highlighting the consistent nature of place names and their ability to withstand culture and language change (Müller-Wille, 1989). In her analysis of Ditidaht place names, Kennedy (2010) describes the names whose meaning is still discernible as "semantically bundled" (p. 241), pointing to the names' descriptive muscle. Cruikshank (1990) describes place names as having "the ability to encode complex ideas into a single word" (p. 64). In other words, one name may pack in meaning related to resources, activity, or the environment's physical appearance.

Indeed, Indigenous place names often provide a literal portrait of the location. Many examples of this can be found in Basso's (1996) seminal work on Western Apache place names, Wisdom Sits in Places. For instance, one Western Apache place name is Tséé Ligai Dah Sidilé, which translates to White Rocks Lie Above in a Compact Cluster (p. 87). As you can see by the photo of Tséé Ligai Dah Sidilé (Figure 5), and as one of Basso's consultants puts it, "its name is like a picture" (p. 38); it describes precisely a cluster of white rocks that sit atop a small mountain. The literal meanings of Western Apache place names are likely important in the context of way finding and resource procurement.

The semantics of place names in the Hul'qumi'num language is comparable to that of the Western Apache. For the purpose of the Stz'uminus Storied Places Digital Atlas, 22 Hul'qumi'num place names relevant to the Stz'uminus First Nation were focused on. Each of the 22 place names, unless their meaning has not been recorded, contain information about the place to which it refers, whether it is resources, activities, ancestors, mythology, or physical appearance (Table 1). Rozen's (1976) preliminary typology of over 300 Hul'qumi'num place 
Figure 5: Tséé Ligai Dah Sidilé, which translates to White Rocks Lie Above in a Compact Cluster, Photo from Basso's (1996) Wisdom Sits in Places (87).

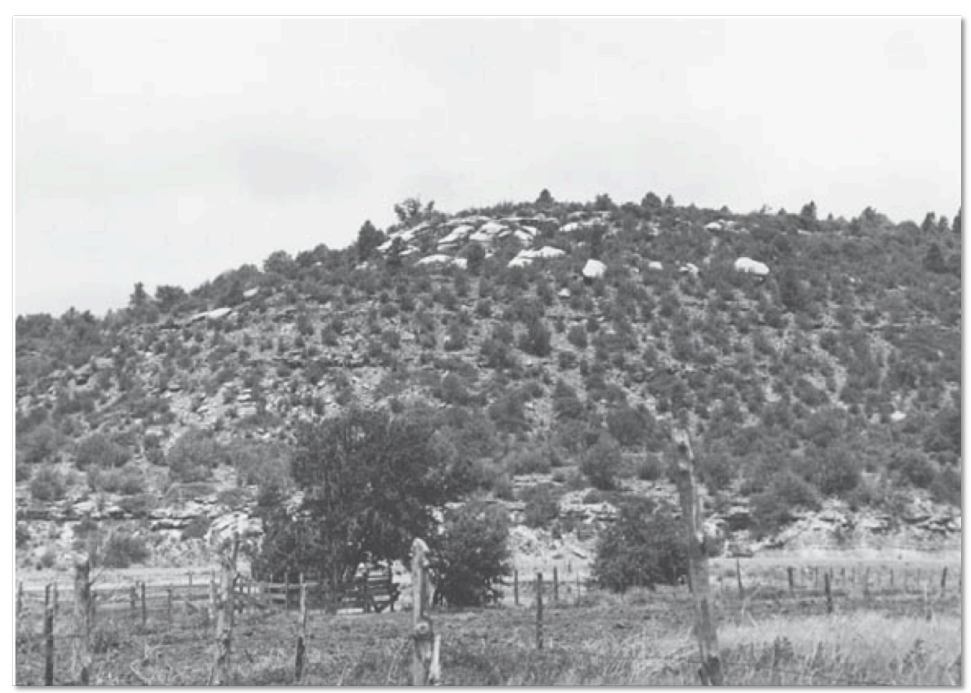


names on Vancouver Island shows that 69 percent of the names are descriptive (p. 275). Thus, Hul'qumi'num place names are comparable to what other scholars have found in their linguistic analyses of Indigenous place names; the majority of the names are semantically descriptive (Kennedy, 2010; Hunn, 1996; Basso, 1984). Therefore, by learning Hul'qumi'num place names and their meanings, one is likely to learn something about the place to which they refer, which makes a place names map a particularly valuable tool in disseminating Indigenous knowledge of the local landscape.

However, unless one is fluent in the Hul'qumi'num language, a static two-dimensional place names map, like the one the Stz'uminus Storied Places Digital Atlas is based off of (Figure 1), provides little linguistic information, such as the name's meaning or pronunciation, making it accessible mainly to experts familiar with the language. An interactive digital map, however, has the ability to include the linguistic details of a place name, allowing Stz'uminus youth, as well as others who are learning the Hul'qumi'num language, to experience the sounds and meanings of the names quite easily. For example, the Stz'uminus Storied Places Digital Atlas provides each place name's English translation, if available, in the place name's pop-up box. The pop-up box also includes an audio file of local Elder Willie Seymour saying the place name in Hul'qumi'num (Figure 6). Thus, the map's potential as a tool for enhancing people's ability to learn the 22 Hul'qumi'num place names is significant. Rather than simply reading the Hul'qumi'num words, which often combine sounds unfamiliar to English speakers, users can hear the names and learn their meanings with a click of a mouse, or the tap of a finger (in the case of touch screen technology), while also seeing where the place is located. By integrating the meanings, pronunciation, and location of each place name into one interactive map, the depth of information a place name contains is more effectively represented. 
Table 1: Hul'qumi'num place names and their meanings

\begin{tabular}{ll} 
Place Name & Translation \\
\hline Xee(y)mutsun & Crying on the beach \\
Hwkw'ulhtun & [water] poured out place \\
Sh(us)tth'upsum & [not recorded] \\
Kw'eyawus & [not recorded] \\
(Hw)qwtaaythun & sturgeon place \\
Thuq'mi'n & spearing place \\
Shwethuqun & (not recorded) \\
Ti'tqumulu little & duck net place \\
Shqw'hi'wun & (not recorded) \\
Xwuthnets & (not recorded) \\
Hwkwitsum & falling into water \\
Hwsuxween & herring spawn place \\
(S)quwinus & beating the chest \\
Hwsaaqw'um & cow parsnip place \\
Xuniimutsten & ancestral name \\
Xwele'elhp & willow tree \\
Q'ulits' & sheltered/protected area \\
Shts'um'inus & bite out of beach \\
Kwi'kwumluhw & little root \\
Xutl'nutstun & way to cross the back end \\
\hline
\end{tabular}

\section{EXPRESSING PLACE-BASED STORIES THROUGH EMBEDDED VIDEOS}

In addition to the linguistic meanings and sounds of Indigenous place names, place names house another important layer of knowledge stories. These stories are a significant part of Indigenous situated knowledge and perspectives of the environment. Whether mythological, historical, or personal, a story associated with a place name may contain many types of information, such as resource procure- 
Figure 6: Pop-up Box with Audio File for the Place Name Xuniimutsten, Map data: Google.

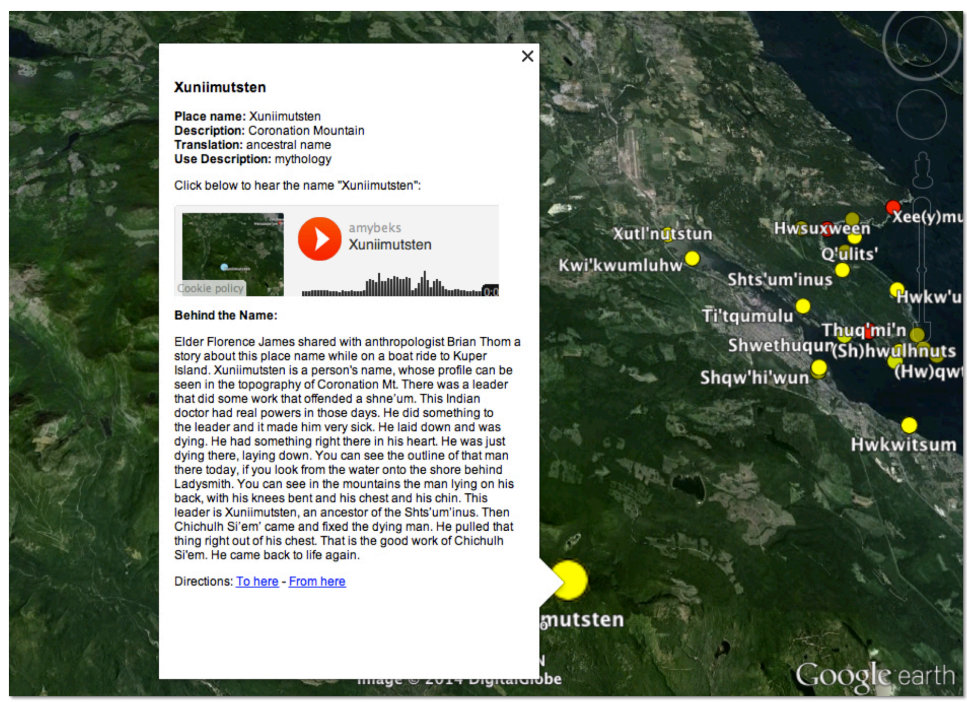

ment, environmental changes over time, collective values, and moral teachings. For example, Hwsuxween in Stz'uminus territory means Herring Spawn Place. During the Stz'uminus Storied Places Digital Atlas project, the youth recorded Elder Willie Seymour describing Hwsuxween as it was when he was a young boy. He describes the place as being a very heavy herring spawn area. He tells the story of how "they put a rope on a bucket ... and when the tide's just right ... you'd throw that bucket out and pull it in, and they had a bucket full of herring. Now you don't see any [herring] come into this harbor" (Seymour, 2013). Mr. Seymour's story of Hwsuxween provides a history of the environment and how resource procurement has changed since he was a boy, giving the listener a deeper understanding of the place name, and thus the place.

Additionally, place names and their stories may incorporate guidelines for behaviour deeply connected to the collective values of the people. Basso's (1996) study of Western Apache place names shows 
that their place name stories are usually of moral instruction. A place name would bring up the physical setting of the place, and with it, a story of moral instruction that happened there. Basso often heard the idea that stories at named places were "like arrows." In other words, the recitation of a place name swiftly conjured up its associated story in the minds of individuals in need of moral teaching. So powerful was the name, it pierced like an arrow and provided directions for appropriate behaviour.

Likewise, Hul'qumi'num place names also incorporate moral and cultural guidelines for behaviour. Elder Willie Seymour's story of Xeeymutsun, meaning Crying on the Beach, describes a place where orphans and widowers journeyed to lament, meditate, and heal. The story is one of how grief and sorrow is expressed in Stz'uminus culture as well as its associated ceremonial practices. Below is a short excerpt from Mr. Seymour's video story of Xeeymutsun:

We are allowed to lament anytime. In our language that's called haanethut, haanethut. Our people didn't just grieve alone. They were helped. Somebody was there with them, and they were never lectured to say, "Oh, you're not allowed to cry." No. If you're overwhelmed with tears, you've got to let it out, as long as it doesn't become a sickness where you're always sad. You allow your sadness to hit, you shed it, and you let it go and live your life, so your life becomes complete.

(Seymour, 2013b)

The video stories embedded at the place names on the Stz'uminus Storied Places Digital Atlas add another dimension of knowledge to the map. Both the video story of Crying on the Beach (Xeeymutsun) and the video story of Herring Spawn Place (Hwsuxween) are embedded at their place marks on the Stz'uminus Storied Places Digital Atlas (Figure 7). The videos appear in the place names' pop-up boxes with the linguistic information discussed earlier. By making each place name's linguistic information, its place-based stories, and location accessible through the digital, interactive map, users can explore 
Figure 7: Pop-up box for Xeeymutsun, Showing the Embedded Video Story, Map data: Google.

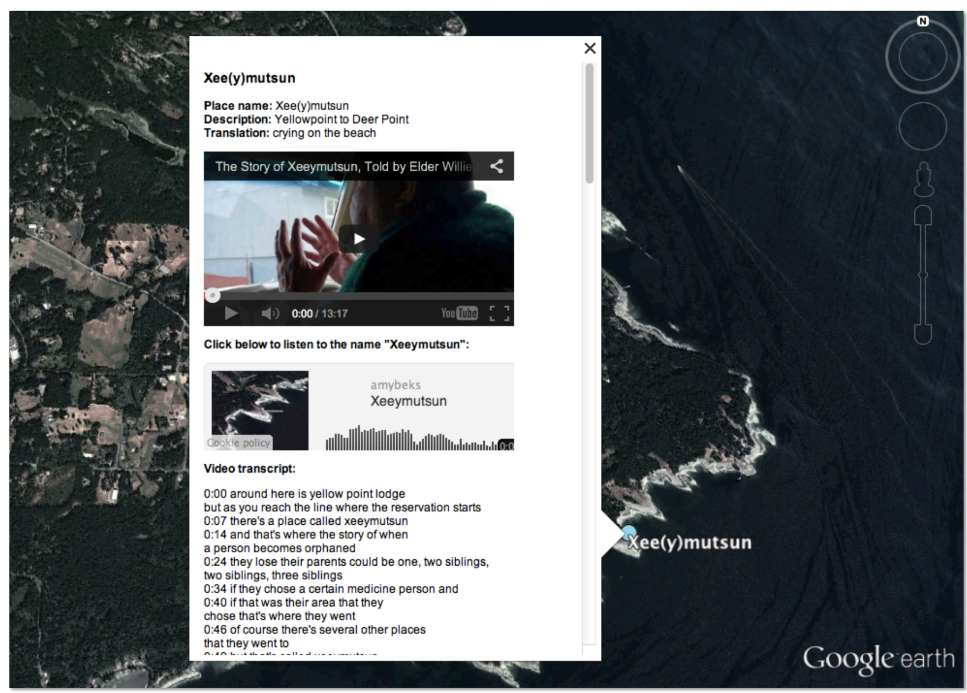

several layers of Indigenous place name knowledge, thereby obtaining a deeper, more holistic understanding of the importance of place names.

\section{COMMUNITY-BASED APPROACH TO PLACE NAME KNOWLEDGE MOBILIZATION}

The ultimate goal of the Stz'uminus Storied Places Digital Atlas project is that both the community-based research process as well as the research product (the digital atlas) will mobilize place-based knowledge about Stz'uminus territory. Throughout the research process, Stz'uminus youth are actively partaking in the documentation of Elders' stories. This aspect of the project contributes to intergenerational knowledge transfer by attempting to bring place name knowledge into active use. By telling stories related to Stz'uminus territory, the Elder passes on valuable information about their culture, 
values, beliefs and ways of life, keeping Stz'uminus history alive in the memories and recordings of the youth involved. Furthermore, the geographical basis for the stories told contributes to all participants' sense of ownership and connection to the environment - an integral part of First Nations culture and an avenue to strengthening personal and collective wellness. Finally, the resulting digital map acknowledges the need for up-to-date technological approaches to knowledge mobilization at a time when youth are becoming increasingly engaged with technology. Not only does the research process propel place-based knowledge into active use, it is hoped that the resulting interactive, digital atlas will continue to promote active use, as the community's youth, and adults, can easily access and share the digital map through their mobile devices (Figure 8).

The community-based research approach and interactivity of the Stz'uminus Storied Places Digital Atlas aims to mobilize place name knowledge in way that does not freeze and objectify traditional knowledge but displays important context and encourages cultural authenticity. Cruikshank (1990) remarks, "detaching names from the context in which they are presented as though they can be objectively isolated and filed on a map gives too little sense of how they are actually used" (p. 55). The digital atlas attempts to represent the context for Hul'qumi'num place names by incorporating the names' meanings, pronunciation, and associated stories on a digital, 3D landscape. Furthermore, mapping workshops, training activities, and manuals will facilitate the diffusion of computer skills needed for Stz'uminus community members to add to and change the digital atlas as they see fit. The free Google mapping technology is accessible and easy for anyone to use. Therefore, instead of the digital atlas becoming an inventory of Stz'uminus traditional ways, the map's ability to include multi-media as well as community members' ability to easily add to and change the map attempts to reflect the fluidity of traditional knowledge.

Indeed, Ingold (2011) points out that when it comes to traditional knowledge, "the important thing, so far as [Indigenous peoples] are concerned, is that the process should keep on going, not that it should 
Figure 8: Stz'uminus Storied Places Digital Atlas Displayed on a Smart Phone Author's image.

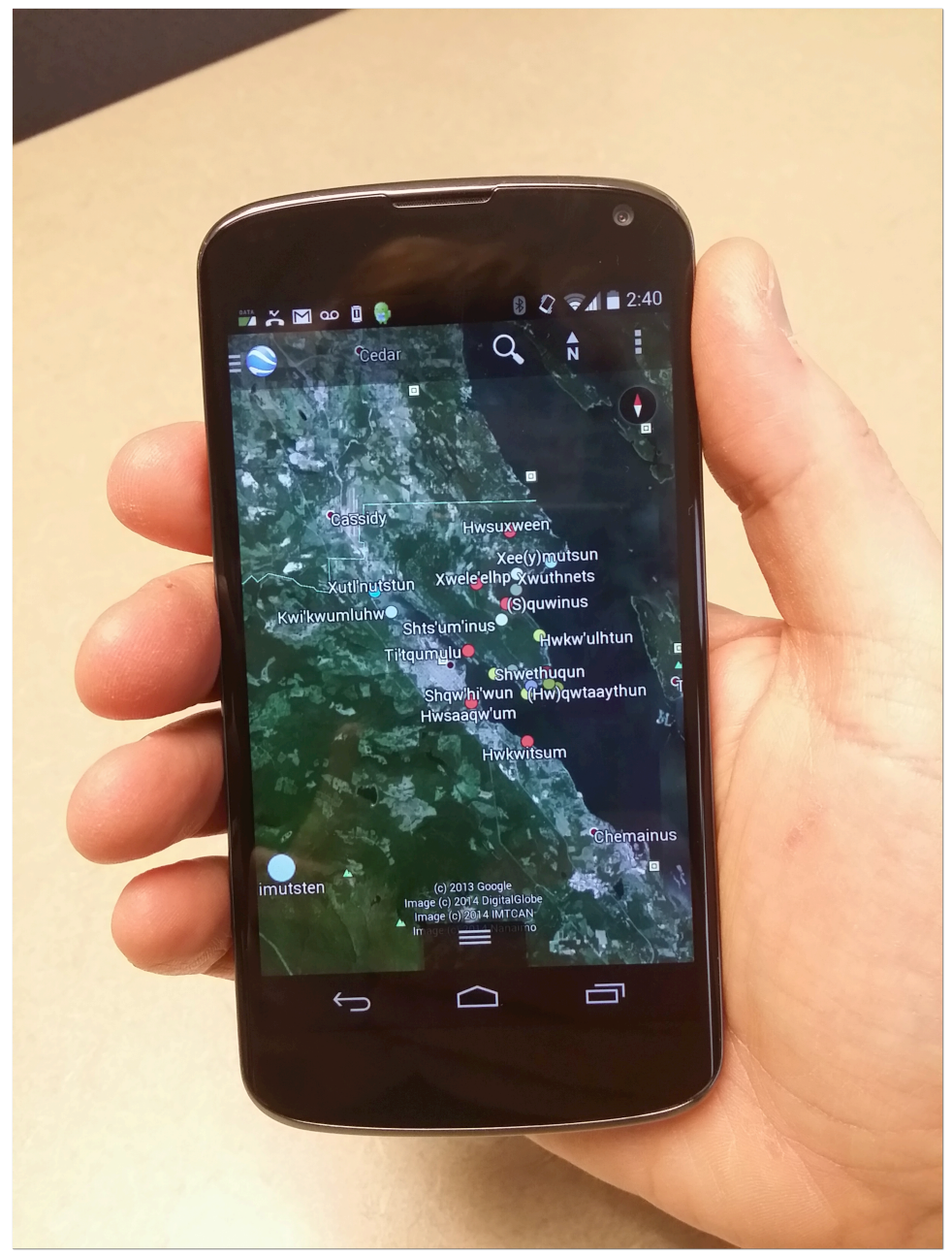


yield precise replicas of past performance" (p. 147). The Stz'uminus community has echoed this sentiment. For example, the community wants to represent the variation in Elders' stories, and I have been asked multiple times whether it is possible to embed more than one Elder's story at a single place mark on the map (which it is). The story-telling process is organic, and there are many important points of view; some stories are almost identical but with subtle differences, yet the community is interested in making sure all those stories are represented. By representing story variations, the place and its name is represented more holistically, and the user of the digital map is aware that all versions are acceptable and important, challenging a static perception of Canadian Aboriginal peoples' culture, and acknowledging that a sense of place exists, lives, and changes with an individual's identity in the context of a dynamic, growing culture.

\section{MAPPING TOOLS}

Two Google mapping tools were explored during creation of the Stz'uminus Storied Places Digital Map prototype: Google Maps Engine (mapsengine.google.com) and Google Earth (www.google.com/earth). In the context of the Stz'uminus Storied Places Project, each tool has its benefits and drawbacks. Both tools are free and relatively easy to use; however, Google Maps Engine is slightly more user friendly than Google Earth. Both Google Maps Engine and Google Earth can be edited and viewed on desktops and laptops, and both tools have mobile applications users can download to their mobile devices.

The main difference between the two mapping tools is that Google Maps Engine is hosted on a cloud-based server and Google Earth is free software that must be downloaded to a local computer in order edit maps. In order to share a digital map created using Google Maps Engine, one can simply share a link to the map hosted in the cloud. However, if one wishes to share a map created in Google Earth, the map must either be shared as a file attached to an email or storage device or as an embedded map on a website page. If the map created in Google Earth is embedded in a website, the link to that web- 
site can be easily shared; however, if the Google Earth map file is shared via email or storage device, the recipient of the file must have Google Earth software downloaded to their local computer to view it. The benefit of the using Google Earth as the main tool for the Stz'uminus Storied Places project is that all the information can be hosted privately on a local server within the community; however, a website would also have to be set up to embed the map and display it publically. The benefit of Google Maps Engine is that it is more user-friendly and easy to share, with a more elegant interface.

The mobile applications for both Google Earth and Google Maps Engine are under development by Google. The current strength of the Google Earth application is that it is available for download on both iPhone and Android mobile phones and its functionality includes displaying videos embedded within the map on mobile phones. Google Maps Engine, on the other hand, is only available on Android and has yet to incorporate the video function; however, this app is regularly being upgraded to include more features, so I think we can expect to see the video feature and an iPhone application some time during the duration of the Stz'uminus Storied Place Project.

\section{Conclusion}

Without their context, Indigenous place names gathered on a map do little to represent the many layers of meaning they contain. According to the literature, one Indigenous-language place name has the potential to contain within it many types of information, including the environment's physical appearance, resource procurement, cultural heritage, and codes for behaviour. The Stz'uminus Storied Places Digital Atlas attempts to represent those layers of knowledge through its digital mapping interface, which is capable of embedding audio, video, and text in the pop-up box of each place name. Thus, the meaning of Hul'qumi'num place names, their pronunciation, and the stories associated with them are represented through multimedia at their locations on the map. The community-based research process where youth collect place-based stories via video is a form of mov- 
ing place name knowledge into use. Furthermore, the digital mapping tools are accessible and easy to use, allowing for creativity and change as well as the authentic representation of Indigenous perspectives of the environment to become a part of the mapping process. In the end, the community will decide which Google mapping tool is best suited for the final Stz'uminus Storied Places Digital Map. However, once Google Maps Engine has incorporated video functionality into its mobile application, Google Maps Engine appears to be best suited for desktop/laptop and mobile usability, sharing, and editing. 


\section{REFERENCES}

Basso, K.H. (1984). Stalking with Stories: Names, Places, and Moral Narratives among the Western Apache. In S. Plattner (Ed.), Text, Play, and Story: The Construction and Reconstruction of Self and Society (19-55). Washington, DC: Proceedings of the American Ethnological Society.

Basso, K.H. (1996). Wisdom sits in places: Landscape and language among the western Apache. Albuquerque: University of New Mexico Press.

Cruikshank, J. (1990). Getting the words right: Perspectives on naming and places in Athapaskan oral history. Arctic Anthropology, $27,52-65$.

Hul'qumi'num Treaty Group (HTG). (2005). Hul'qumi'num Snuhuwmuhw - Selected Place Names within the Core Traditional Territory. Retrieved from http://www.hulquminum.bc.ca/pubs/Place_ Names_maps_2005.pdf

Hunn, E. (1996). Columbia Plateau Indian place names: what can they teach us? Fournal of Linguistic Anthropology, 6(1), 3-26. ${ }_{525 / \text { jin.1 } 19966.13}$

Ingold, T. (2000). The Perception of the Environment: Essays on Livelihood, Dwelling and Skill. London: Routledge. http://dx.doi.org/10.4324/9780203466025

Kennedy, D. (2010). Topogeny Among the Ditidaht. In David Beck, (Ed.) A Festschrift for Thomas M. Hess on the Occasion of his Seventieth Birthday (pp. 226-253). Whatcome Museum Publications.

Müller-Wille, L. (1989). Place names, territoriality and sovereignty: Inuit perception of space in Nunavik (Canadian Eastern Arctic). Schweizerische Amerikanisten-Gesellschaft Bulletin, 53(54), 1990,1721.

Peluso, N.L (1995). Whose Woods are These? Counter-Mapping For- http://dx.doi.org/10 est Territories in Kalimantan, Indonesia. Antipode, 27(4), 383-406. ${ }_{1995 . t b 00286 . x}$

Rozen, L.D. (1972). Place-names of the Island Halkomelem Indian People. M.A. thesis, Department of Anthropology and Sociology, University of British Columbia.

Stz'uminus First Nation. (n.d.) Community Map. Retrieved from http://www.stzuminus.com/our-story/community-map/ 
Stz'uminus First Nation. (n.d.) Our Story. Retrieved from http://www. stzuminus.com/our-story/

Thorton, T.F. (1997). Anthropology Studies of Native American Place Naming. American Indian Quaterly, 21(2), 209-228. https://circle .ubc.ca/bitstream/id/85227/UBC_1985_A8 http://dx.doi.org/10.2307/1185645

Usher, P.J. (2003). Environment, Race and Nation Reconsidered: Reflections on Aboriginal Land Claims in Canada. Canadian Geographer, 47(4), 365-382. h http://dx.doi.org/10.1111/j.0008-3658.2003.00029.x

Wonders, C.W. (1987). Native Claims and Place Names in Canada's Western Arctic. The Canadian fournal of Native Studies, 7(1), 111120.

Willie, S. (2013). The Story of Hwsuxween (S. Louie, Interviewer) [Video file].

Willie, S. (2013b). The Story of Xeeymutsun (S. Louie, Interviewer) [Video file]. 